\title{
Effectiveness of Geogrids on Rutting and Bearing Capacity of Sub-base Course
}

\author{
Ali Reza Mardookhpour \\ Department of Civil Engineering, Islamic Azad University, Lahijan Branch -Iran \\ e-mail: alireza.mardookhpour@yahoo.com
}

\begin{abstract}
Geogrids are being used in transportation application often in embankment construction due to their ease of construction and economy compared to traditional methods. Utilizing polymer materials in order to improve the performance of road structure is based on two factors, decreasing deformation and increasing bearing capacity. In this study geogrids were tested to check the ability of increasing load carrying capacity for highway projects. The purpose of this research work was to find a relation between the loading of the geogrid, the thickness of the aggregate layer and its bearing capacity. This would normally lead to an investigation on the lateral restrain behavior of a geogrid. According to the results obtained from soil mechanics laboratory, it could be demonstrated that by utilizing geogrids, the probability of occurring rutting decreases $30 \%$ and the bearing capacity of soil increase $40 \%$ respectively .
\end{abstract}

Key words: geogrids, sub layers, bearing capacity, rutting, dynamic loads, rutting

\section{Introduction}

Building haul and country roads (unpaved roads) are based on the allowable rut depth which may occur during the service life. The rutting is related to the number of load cycles. But in the field of road constructions with paved capping, rutting is not acceptable. Because everything will be done to prevent rutting in such a situation that the rut depth isnot a measurement to predict the performed bearing capacity of the sub grade or base. Based on the fact that the reinforcing effect of the geogrid in haul and country roads over soft soil can be assessed by a decreasing rut depth or an increased number of load cycles, it has to be taken into account that this will not be a sufficient way to estimate the performance of paved roads. The deformations caused by the rutting on unpaved roads are partly reflected in the geogrid. This activates tensile stresses in the geogrid up to a certain rate of elongation. Even low deformations are an indication for tensile stress in the geogrid which can be determined by using the stress-strain graph of a widewidth tensile test (Mofiz et al. 2004). Here are measurements required which indicate the bearing capacity of the structure by using the modulus of CBRvalue.

\section{Methodology}

In this study a cohesive soil with varying water contents was used as sub grade at three different bearing capacity stages. The layer thicknesses and the grain size have been chosen according to the test cylinder to prevent effects of the limited diameter. The road structures have been built in a circular steel cylinder with a diameter of $1.6 \mathrm{~m}$ and a height of $1.3 \mathrm{~m}$ (Fig. 1).

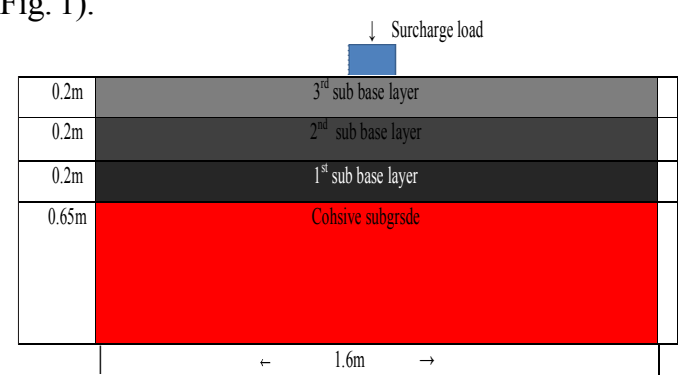

Fig.1. Layer structure in the test 
The range covered CBR-values of $1.1 \%, 2.2 \%$ and 5 $\%$. Several layers combinations of crushed gravel $0 /$ $32 \mathrm{~mm}$ and Enkagrid MAX 40 have been investigated to estimate the effect of the geogrid in unbound sub base layers. The biaxial polypropylene geogrid has an ultimate tensile strength of $47 \mathrm{KN} / \mathrm{m}$ at a strain at break of $10 \%$. For single layer situations the geogrid was placed directly on the sub grade. In case of a multilayer system the second layer was placed on top of $30 \mathrm{~cm}$ of aggregate. The gravel of the sub base has been compacted to Proctor densities between 0.85 and 1.02 depending on the bearing capacity of the sub grade and the use of geogrids. A dynamic load has been applied in each test set up by using a circular steel stamp. The diameter of the load stamp was $0.3 \mathrm{~m}$ and is comparable with the contact area of a two wheeler. Depending on the test combinations a load of $30 \mathrm{kN}$ respectively $50 \mathrm{kN}$ was applied to the load stamp. The number of load cycles at a frequency of $\mathrm{f}=2 \mathrm{~Hz}$ ranged from 10,000 to 50,000 . To prevent effects of the steel cylinder its walls have been covered by a slip foil. A Proctor density DPR $\geq 0.9$ was only be achieved in case a geogrid was applied. This effect reduces by an increasing bearing capacity of the foundation soil. There is nearly no effect regarding this effect wasn't present with a CBR $>5 \%$, because a Proctor density of DPR $=1.0$ could be easily achieved. The tests have shown that a Proctor density of DPR $\geq 0.98$ is needed to get consistent results to predict the performance of the construction.

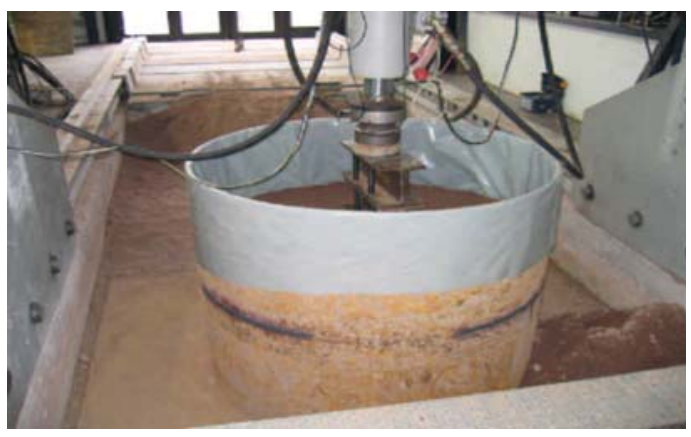

Fig. 2. Layer in the test cylinder

\section{Results and Discussion}

From comparisons between un-reinforced and reinforced sections on a sub grade with $\mathrm{CBR}=1.1 \%$ the conclusion could be drawn that the Proctor density has been increased by 5 to $10 \%$ while using geogrid. As expected an increasing bearing capacity of the sub grade and an increasing layer thickness of the sub base goes with a reduction of the depth. Compared to the various layer structures the reduction caused by a single layer of geogrid reached $40 \%$ on top of $0.2 \mathrm{~m}$ reinforced aggregate and for the use of two geogrid layers $60 \%$ after two times $0.3 \mathrm{~m}$ aggregate. The bearing capacity of the sub grade was in both situations $\mathrm{CBR}=1.1 \%$. A reduction of the rutting due to a second geogrid layer was only been measured at $\mathrm{CBR}=1.1 \%$ of the sub grade. The largest deformations have been determined exactly underneath the load stamp where a strain gauge and a pressure measurement device have been placed. They reached from $0.65 \% \leq \mathrm{e}<1.42 \%$ in the single layer situation. At the edges of the steel cylinder the elongation converged to $\mathrm{e}=0 \%$. The elongations caused in the second geogrid layer have been even smaller and between $0.4 \% \leq \mathrm{e}<$ $0.55 \%$. Figure 3 contains a sketch where the pressure and strain gauges have been placed during the tests. The maximum elongation of $\mathrm{e}=1.25 \%$ has been reached at $105 \mathrm{~mm}$ sink depth for reinforced situation. The internal stress distribution in the sub grade was measured with a flat jack and earth-pressure gauges. The stress gauges have been installed approximately $0.05 \mathrm{~m}$ under the sub grade surface and covered with soil to provide continuous friction behavior in the interface between the different soil and geogrid layers. Figure 4 shows such a measurement for the effect of the sub base layer thickness of an unreinforced situation on a sub grade with $\mathrm{CBR}=$ $1.1 \%$ and layer thicknesses of $0.2 \mathrm{~m}$ and $0.6 \mathrm{~m}$. It is clearly visible that a thicker sub base $(0.6 \mathrm{~m})$ led to an improved load distribution over a larger area with a lower peak value directly underneath the load stamp. The curve of the 0.2 $\mathrm{m}$ sub base layer situation might back up the conclusion that a bearing or deep-seated failure occurred during the loading. That's in line with the observed rutting and the cracks at the surface of the sub base as shown in Figure 5.Figure 6 gives an indication of the effect of a geogrid compared to the unreinforced situations at $\mathrm{CBR}=1.1 \%$ and $\mathrm{CBR}=5 \%$ of the sub grade. Table 1 contains an overview of the optimum layer thickness to improve the bearing capacity by the use of geogrid compared to the un-reinforced situation.

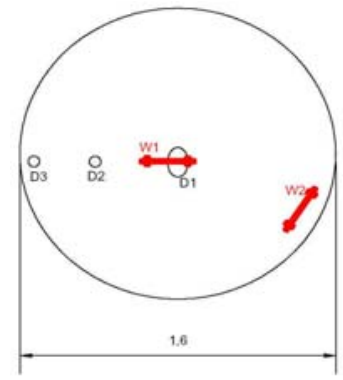

Fig. 3. Pressure and strain gauges 


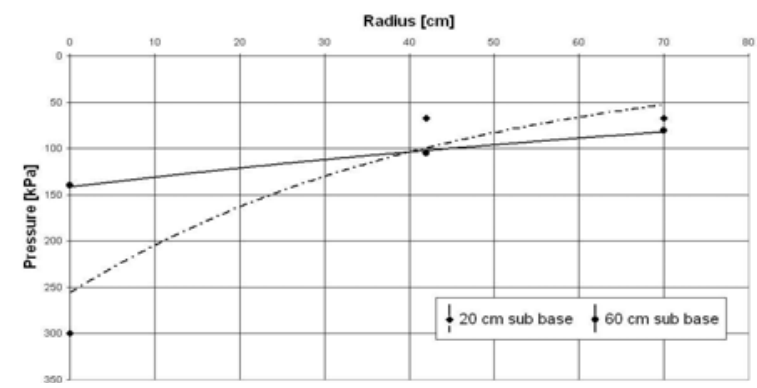

Fig. 4. Stress distribution in the sub grade $(\mathrm{CBR}=1.1 \%)$ depending on the layer thickness without a geogrid

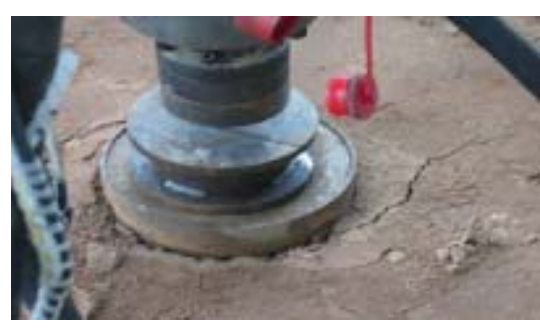

Fig. 5. Cracks at the sub base surface

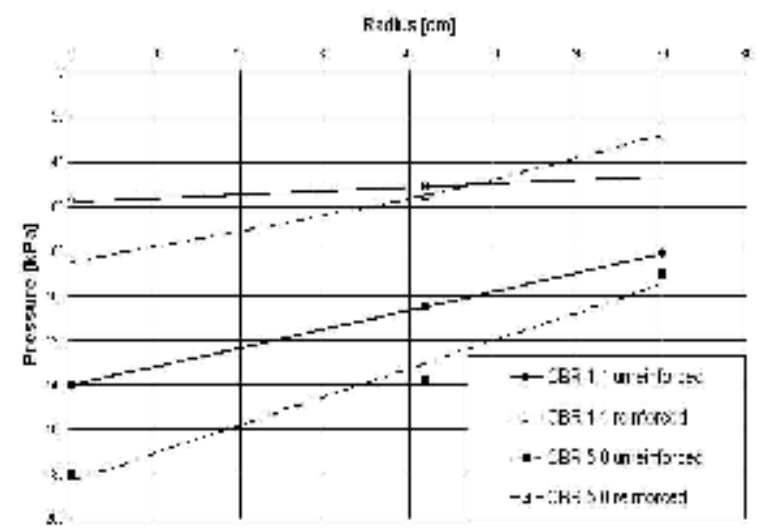

Fig. 6. Stress distribution improvement in the sub grade layer underneath a $0.6 \mathrm{~m}$ of aggregate

Table 1. Optimum layer thickness to improve the bearing capacity

\begin{tabular}{ccc}
\hline $\begin{array}{c}\text { CBR sub grade } \\
(\%)\end{array}$ & $\begin{array}{c}\text { Thickness of } \\
\text { subbase layer } \\
\text { (cm) }\end{array}$ & $\begin{array}{c}\text { Improvement } \\
\text { of the bearing } \\
\text { capacity }(\%)\end{array}$ \\
\hline 1.1 & 60 & 35 \\
2.2 & 40 & 40 \\
5.0 & 40 & 17 \\
\hline
\end{tabular}

According to the results the effect of the geogrids on the compaction ratio was significantly higher on low bearing capacities and reached its maximum at $\mathrm{CBR}=1.1 \%$ in aggregate layer thickness of $0.4 \mathrm{~m}$. Also the results of the tests based on the rut depth have not led to a minimum thickness requirement. In this case an improvement is achieved by simply installing geogrids independently from the actual layer thickness. By utilizing geogrids, the probability of occurring rutting decreases $30 \%$ and the bearing capacity of soil increase $40 \%$ respectively.

\section{Acknowledgements}

The writer whishes to thank the Islamic Azad University, Lahijan Branch, for supporting software and equipment.

\section{References}

Babu, G. L.2006. An introduction to soil reinforcement and geosynthetics. Universities Press. Hyderabad, India.

Ghiassian, H. and M. Jahannia. 2004. Influence of encapsulated geogrid-sand system on bearing capacity and settlement characteristics of reinforced clay, International Journal of Civil Engineering 2(1):45-53.

Giroud, J.P. and L. Noiray.1981. Geotextile reinforced unpaved road design. ASCE, Journal of the Geotechnical Engineering Division 107:1233-1254.

Li, A.L., and R.K. Rowe. 2001. Influence of creep and stress-relaxation of geosynthetic reinforcement on embankment behaviour. Geosynthetics International 8(3):233-270.

Mofiz, S. A., M. R. Taha. and D. C. Sharker. 2004. Mechanical stress-strain characteristics and model behavior of geosynthetic reinforced soil composites. In: 17th ASCE Eng.Mechanics Conf. pp. 23-31.

Plemeria, E. M.and L. G. Mello.2003. Interaction between soils and geosynthetic layers in large-scale ramp test.University of Brasilia.

Retzlaff, J., U. Turczynski and S.Schwerdt. 2009. The effect of geogrids under unbound sub base layers. University of Applied Sciences Anhalt. Germany.

Saran, S. 2006. Reinforced soil and its engineering application. I. K. International Pvt. Ltd. New Delhi, India. 
Nepal Journal of Science and Technology Vol. 15, No.1 (2014) 77-80 